\title{
Passados (im)perfeitos ou a ótica buarqueana sobre o Império do Brasil na América
}

\author{
(Im)perfect pasts. Or a Sérgio Buarque's \\ portrayal on the Brazilian empire in America
}

Giselle Martins Venancio*

André Furtado ${ }^{* *}$

\section{RESUMO}

Este artigo aborda as inovações editoriais e historiográficas propostas pela coleção História Geral da Civilização Brasileira (HGCB), sob a direção de Sérgio Buarque de Holanda, entre 1960 e 1972 . Tem como foco principal os deslocamentos que permitiram ampliar a abordagem da tópica do Império Brasileiro sob uma ótica que o incorporava às questões da historiografia latino-americana. Ao tratar o Império de uma perspectiva que desqualificava os marcos cronológicos que o instituíam, Sérgio Buarque considera um elemento exclusivo da historiografia brasileira em relação à América, a existência de uma monarquia no século XIX, de modo a integrá-lo nas discussões sobre o continente.

Palavras-chave: HGCB; Coleções; Império do Brasil; Sérgio Buarque de Holanda.

\section{Abstract}

This article addresses the editorial and historiographical innovations that were proposed by the collection General History of the Brazilian Civilization (HGCB in Portuguese), under the direction of Sérgio Buarque de Holanda, from 1960 to 1972 . Its main focus are the changes that allowed for a broader approach of the Brazilian Empire topic under an optic which incorporated it into the LatinAmerican historiography. By treating the Empire under the perspective which disqualified the chronological milestones which instituted it, Sérgio Buarque considers as an exclusive element of Brazilian historiography on America, the existence of a XIX century monarchy, in such way as to integrate this into the discussions about the continent.

Keywords: HGCB; Collections; Brazilian Monarchy; Sérgio Buarque de Holanda.

\footnotetext{
* Universidade Federal Fluminense (UFF). Bolsista de produtividade do CNPq e Cientista do Nosso Estado/Faperj. Rio de Janeiro, RJ, Brasil. giselle@historia.uff.br

** Doutorando em História, Universidade Federal Fluminense (UFF). Bolsista Capes. Rio de Janeiro, RJ, Brasil. afurtado@id.uff.br
} 


\section{POR UMA História IBERO-AMERICANA}

Em maio de 1967, Warren Dean, então professor da Universidade do Texas (UT), escreveu na Hispanic American Historical Review uma resenha da História Geral da Civilização Brasileira (HGCB), coleção que vinha sendo editada pela Difusão Europeia do Livro (Difel) sob a direção de Sérgio Buarque de Holanda desde $1960^{1}$ e que, até aquela data, já havia publicado cinco volumes, correspondentes aos períodos da Colônia e do Império. ${ }^{2}$ A presença da resenha nessa prestigiada revista evidencia a importância que o empreendimento editorial vinha adquirindo como referência basilar para os estudiosos da História. Ao longo de seu texto, Dean direciona a análise, em particular, ao segundo volume referente ao Tomo II - O Brasil Monárquico -, conferindo ênfase aos capítulos de autoria de Sérgio Buarque, Fernando Henrique Cardoso e Francisco Iglésias. Elogioso, destaca o fato de esses autores serem atentos à conjugação de fatores econômicos e sociais na escrita da História, e conclui que a HGCB deveria ser classificada entre as melhores contribuições à História latino-americana (Dean, 1967). O comentário de Warren Dean ${ }^{3}$ na revista aponta para uma questão aparentemente surpreendente: a vinculação da HGCB à história latino-americana, ${ }^{4}$ pois, frequentemente, a inserção mais direta dessa coleção é dada pelos pesquisadores à tradição das brasilianas, projetos editoriais que tinham como seu principal objeto o Brasil.

Desde os anos 1930, tinham surgido no país diversos esforços no mercado editorial cuja principal marca consistia em publicar estudos dedicados às temáticas nacionais de forma intensificada e que haviam encontrado sua expressão máxima e modelo ideal na forma de coleções. Entre elas destacava-se a Brasiliana, fundada em 1931 pela Companhia Editora Nacional no interior da coleção Biblioteca Pedagógica Brasileira, da qual se emanciparia no ano de 1958 (Venancio, 2002). Inicialmente dirigida por Fernando de Azevedo, havia nela o plano de reunir um saber de caráter compacto e natureza enciclopédica sobre o país nos diversos campos do conhecimento, o que se manteve mesmo após a mudança de seu coordenador, em 1956, quando Américo Jacobina Lacombe assumiu o projeto. ${ }^{5}$

Sua representatividade foi tamanha que outras editoras lhe seguiram o exemplo e também lançaram suas coleções. Esse foi o caso da Documentos Brasileiros, impressa a partir de 1936 pela Livraria José Olympio Editora, empreendimento de suma importância para a trajetória intelectual de Sérgio Buarque de Holanda porque inaugurado, justamente, com o primeiro texto de sua autoria transformado em livro: Raízes do Brasil. Além de volume inicial da coleção, esse livro era 
também a sua obra de estreia, seguido pelas edições de Caminhos e fronteiras (1957) e Visão do paraíso (1959), publicadas na mesma coleção. ${ }^{6}$

A HGCB se insere, portanto, nessa tradição das brasilianas, porém, sua edição corresponde a um momento decisivo no processo de especialização dos saberes no país, o que se destaca nas inúmeras diferenças apresentadas em seus livros em relação às coleções surgidas anteriormente. Essas mudanças aparecem no que se refere, por exemplo, à organização dos textos, pois, de maneira distinta das coleções prévias, a HGCB se caracteriza pela estrutura em forma de coletânea. Outro traço inovador em seu projeto foi o empenho de seus organizadores para viabilizar a participação de colaboradores ligados às universidades então em expansão no Brasil e, mais particularmente, à Universidade de São Paulo (USP).

Além disso, embora o projeto da HGCB previsse que os artigos deveriam tratar exclusivamente da história do Brasil, a introdução, por Sérgio Buarque de Holanda, de aspectos que buscavam estabelecer uma análise historiográfica que relacionasse o país aos eventos históricos mundiais e aos processos da América Latina, em particular, foi também inovadora. A inserção, por exemplo, de quadros cronológicos ao final de cada Tomo, envolvia os eventos da história nacional em uma perspectiva mais ampla. É possível supor que essa inclusão não tenha sido uma sugestão de Sérgio, mas um resultado de decisão editorial cujo objetivo era sintetizar a história do Brasil e relacioná-la à história das civilizações. No entanto, é plausível crer, igualmente, que o diretor da coleção corroborasse e estimulasse a ideia.

Contudo, apesar das inúmeras inovações de caráter editorial da HGCB, este artigo abordará um aspecto de cunho historiográfico também introduzido pela coleção: os deslocamentos que permitiram ampliar a abordagem da tópica do Império Brasileiro sob uma ótica que o incorporava às questões da historiografia latino-americana. Ao abordar o Império de uma perspectiva que, na realidade, desqualificava os marcos cronológicos que o instituíam, Sérgio Buarque considerava um elemento exclusivo da historiografia brasileira em relação à América - a existência de uma monarquia no século XIX - de modo a integrá-lo nas discussões sobre o continente.

A PROPOSTA EDITORIAL DA COLEÇÃo

História Geral da Civilização Brasileira

Mal tinha ingressado Sérgio Buarque de Holanda, de forma definitiva, na então Faculdade de Filosofia, Ciências e Letras (FFCL) da USP, ${ }^{7}$ e já percorria os principais círculos do mundo intelectual brasileiro em busca de autores para 
o empreendimento editorial que vinha dirigindo junto à Difel. Em carta datada de 20 de novembro de 1961 - na qual foi incluído como segundo destinatário Paul Jean Monteil, editor da Difel $^{8}$-, Wanderley de Araújo Pinho, catedrático em História do Brasil na Universidade da Bahia, ${ }^{9}$ respondia a Sergio Buarque o convite feito para que escrevesse um capítulo sobre essa antiga província. ${ }^{10}$ Tratava-se de uma pesquisa encomendada para dar sequência ao empreendimento da coleção HGCB, cujos volumes haviam começado a ser impressos no ano anterior.

Antes disso, e a despeito de todo o empenho dos responsáveis em selecionar um grupo seleto de colaboradores, o empreendimento havia gerado dúvidas no meio acadêmico. Pelo menos, é o que se observa na correspondência trocada entre o historiador Francisco Iglésias e sua colega de ofício Alice Piffer Canabrava, então professores respectivamente das Faculdades de Ciências Econômicas na Universidade de Minas Gerais (UMG) e da USP. Nas palavras de Iglésias a Canabrava, "a obra" ficava muito aquém e perdia muito "quando comparada à edição francesa - a realmente monumental Histoire générale des civilisations". ${ }^{11}$

Na imprensa, porém, a coleção vinha sendo noticiada como um novo trabalho sobre o país, que versaria sobre vários assuntos, "abrangendo assim o estudo não somente do aspecto histórico, mas o etnológico, o geográfico, $\mathrm{o}$ religioso, o político etc." (Fatos e autores, 1960, p.4). Os periódicos a entendiam como representante do "primeiro esforço coletivo de reconstituição do passado do Brasil” (Livros: mercado interno, 1960, p.43), além de registrarem a distinção da coleção, marcada pelo esforço de uma escrita conjunta da história pátria, na trilha dos exemplos de obras como The new Cambridge Modern History (Potter, 1957-1979) e a Historia mundi (Kern et al., 1952-1961).

Pioneira em traduzir para o português obras mais voltadas às Ciências Sociais e à Linguística, a editora Difel, entusiasta e fomentadora central do projeto dirigido por Sérgio, tivera sua gênese na importação de livros e revistas que, junto de sua esposa, Juliette, Paul Monteil iniciou após a Segunda Guerra Mundial, em 1946, mediante a fundação da Livraria Francesa na cidade de São Paulo. De pronto, o lugar se tornara um espaço para a reunião de intelectuais, frequentado, em especial, por muitos professores franceses que atuavam na USP, a exemplo do sociólogo Roger Bastide.

Com o êxito alcançado nos negócios, a editora foi efetivamente criada pelo casal, em fevereiro de 1950, quando o sucesso da Livraria já era tamanho que resultou na abertura de uma filial no Rio de Janeiro, à época capital do país. Graças à transação comercial com o grupo francês Garnier Frères, atuante no 
mercado brasileiro desde o século XIX, mas, sobretudo, após estabelecer sua sede em São Paulo, no ano de 1951, bastou apenas uma década para que a Difel passasse a figurar entre as maiores casas editoriais do Brasil (Hallewell, 1985). A editora teve, inicialmente, um olhar direcionado, em grande medida, aos estudantes universitários (Castro, 1974, p.46), público-alvo então em constituição no país e que se mantinha na condição de terreno fértil e ainda por ser explorado.

Em seu catálogo constavam os livros das versões francesas da História Geral das Ciências (HGCiências) (Taton, 1959-1967) e da História Geral das Civilizações (HGC) (Crouzet, 1955-1958), que precederam, inspiraram e coexistiram com o formato da versão brasileira. A HGC contou até mesmo com a participação de professores da FFCL-USP que depois iriam se envolver com a HGCB, como Eurípedes Simões de Paula e, em especial, Pedro Moacyr Campos, convertido, posteriormente, em assistente de Sérgio Buarque.

Considerados esses aspectos, convém salientar que, afora todos os traços de distinção aludidos, diferentemente das coleções Brasiliana e Documentos Brasileiros, a estrutura impressa da coleção HGCB também foi pensada por um viés editorial que a dividiu em dois principais grupos, quais sejam, a parte dos "Tomos" e a dos "Volumes". Logo, os primeiros ficavam responsáveis por compor, em seu conjunto, as épocas da Colônia, do Império e da República. E, aos segundos, cabia reunir "livros" que seriam então formados por "capítulos", mais ou menos autônomos, em razão do tratamento pormenorizado que a eles era resguardado, para versarem sobre os períodos mencionados. Sérgio Buarque dirigiu os dois primeiros tomos - a Colônia e o Império -, ficando a parte sobre a República sob a organização de Boris Fausto. Os livros correspondentes à fase buarqueana da coleção contaram, ainda, com o aval acadêmico explícito concedido pela USP, sob os auspícios e o nome da FFCL, conforme inscrição impressa nos paratextos editoriais dos volumes editados.

\section{A RECEPÇÃO DA COLEÇÃO E O RECONHECIMENTO DE SÉrgio BuARque historiador}

Membro da primeira Diretoria da Associação de Professores Universitários de História (APUH) - convertida depois em ANPUH, pela incorporação da palavra Nacional em sua sigla - e, por muitos anos, integrante de seus círculos dirigentes, Sérgio Buarque figurou de maneira relativamente recorrente nos Anais dos encontros promovidos pela entidade nos anos 1960, 
momento da publicação da HGCB sob sua direção. Sua atuação se fazia sentir pela presença nos eventos promovidos pela instituição e, sobretudo, mediante citações à coleção, num processo de qualificação paulatina, mas crescentemente hegemônica, dos seus estudos historiográficos. Durante o I Seminário da associação, que ocorreu na cidade paulista de Marília, em 1961, o catedrático compôs a direção do evento e presidiu uma das mesas-redondas. Na ocasião, só haviam sido publicados os dois primeiros volumes da HGCB, mas seus livros já apareciam referidos por historiadores que os reconheciam como possuindo proposta de inovação na historiografia brasileira.

O nome e os textos mais diretamente ligados a Sérgio Buarque chegaram a aparecer de forma destacada, até mesmo na conferência proferida pelo também historiador Arthur Cezar Ferreira Reis, em 1961. ${ }^{12}$ Reis argumentou que, até aquele momento, o passado do país não havia recebido muita ênfase por um viés valorizador da diversidade local. Para tanto, ao endossar o diagnóstico da precedência da Sociologia sobre a História, enquanto disciplina mais bem estabelecida no campo acadêmico do período, recorreu à citação de Roger Bastide para dar ênfase à imperiosidade de pesquisas voltadas aos contrastes de fundação, por ele entendidos como eminentemente culturais (Reis, 1961, p.66-67). Apontando para as lições e heranças legadas por Capistrano de Abreu - à época visto, referenciado e celebrado como o estudioso de maior destaque do passado brasileiro de todos os tempos, espécie de marco zero ou divisor de águas historiográfico - como as únicas meritórias de considerações, Reis fez questão de citá-lo. ${ }^{13} \mathrm{O}$ texto aludido na conferência da APUH foi o prefácio que Capistrano de Abreu havia escrito para a edição mais recente do livro intitulado História do Brasil: 1500-1627, atribuído a Frei Vicente de Salvador (Salvador, 1918). Nele constava a descrição do franciscano como um dos primeiros a atentar para a pluralidade do passado da América portuguesa, o que, ainda nas palavras de Reis, tinha servido de exemplo a Capistrano, pois, no dizer do palestrante, o livro Capítulos de história colonial (Abreu, 1907) abordava o aspecto regional. A referência a Capistrano serviu ainda a Reis para mensurar a importância de Sérgio como organizador inicial da coleção HGCB, quando em sua conferência afirmou que "em nossos dias, Sérgio Buarque de Holanda, na 'História da Civilização Brasileira', não ignorou o critério regional. Está ali, além do quadro físico, a natureza em ser, a ocupação do litoral, a ocupação da Amazônia, do extremo sul, do centro-oeste" (Reis, 1961, p.66-67).

Apenas com a impressão dos dois primeiros volumes alusivos à época colonial, quando do discurso de Reis - que já se encontrava entre os maiores colaboradores dos livros editados e dos vindouros, se considerarmos o 
planejamento prévio da coleção $\mathrm{HGCB}^{14}$-, é lícito supor que o amazonense estivesse mobilizando uma estratégia narrativa para, ele próprio, colocar-se como historiador referencial. Num só tempo, Reis prendia-se aos espólios letrados de seu antigo preceptor, Capistrano de Abreu, postando-se como uma espécie de continuum geracional, bem como visava se aproximar de Sérgio Buarque e do empreendimento editorial por ele coordenado.

Se a alusão a Buarque de Holanda se fez presente na ata do I Encontro da Associação, nos congressos subsequentes os usos da HGCB se tornariam ainda mais frequentes.

Em 1965, o comentário da professora Olga Pantaleão, da FFCL de Marília, ecoado durante o debate que se seguiu à fala de sua colega Antônia Wright, da FFCL-USP, por exemplo, serviu para que ela acrescentasse um texto de sua autoria na coleção da Difel (Pantaleão, 1962), como uma forma a mais de explorar os documentos reproduzidos na obra Britain and the independence of Latin America (Wright, 1965, p.555-556).

Referência contígua, a temática do comércio durante os séculos XVI e XVII na HGCB apareceu na comunicação denominada "Os projetos de colonização e comércio toscanos no Brasil ao tempo do grão-duque Fernando I (1587-1609)", do próprio Sérgio Buarque (Holanda, 1967, p.157). Esta foi apresentada no Simpósio de 1967 e, em princípio, pode ser lida como uma das últimas pesquisas nas quais se observam reflexões mais demoradas do historiador sobre a colônia, período visto, então, como privilegiado pelo autor, embora, como se demonstrará adiante, uma de suas grandes teses no planejamento da coleção consistisse em relativizar os marcos cronológicos de 1822 e 1889 como datas limites para o período imperial brasileiro. E por esse motivo, talvez, a rígida classificação entre as pesquisas sobre o período colonial e monárquico sequer fizesse sentido para ele.

Outra forma de recepção da HGCB nos anais da A(N)PUH emergiu em um texto assinado em coautoria, apresentado no simpósio realizado em Goiânia, nos anos 1970. Nessa circunstância, a coleção foi usada para sustentar a tese segundo a qual a cidade de São Paulo de fins do oitocentos e início do século seguinte apresentava uma crescente singularização face ao desenvolvimento galopante da economia cafeeira (Castro; Scarano, 1971, p.718). Uma das autoras do artigo, Jeanne de Castro, fora orientanda de Sérgio Buarque no doutorado que fez na FFCL-USP, momento também singular de sua participação na HGCB (Castro, 1971). Afinal de contas, Castro integrou o grupo de herdeiros intelectuais acadêmicos do organizador do projeto e, provavelmente 
por essa razão, teve parte de suas pesquisas incorporada ao plano do empreendimento editorial da Difel, sobretudo no Tomo II.

Nos livros editados para compor essa parte da coleção, até 1971 - portanto, já quase no limite dos impressos destinados ao período do Brasil imperial -, à lista de discentes da USP podem-se acrescentar os nomes de Teresa Schorer Petrone e Frank Goldman como colaboradores, bem como o de Suely Robles Reis de Queiroz, como auxiliar da última publicação referente ao período monárquico, além de Boris Fausto, escolhido para suceder Holanda na direção do projeto.

Além disso - e este dado é relevante -, ainda no âmbito dos encontros da A(N)PUH, cabe mencionar a fala de Alice Piffer Canabrava, outra colaboradora da HGCB. Isso porque, em 1975, ela alocou alguns volumes da coleção no balanço bibliográfico que fez a propósito da área que, de forma homônima ao livro de Celso Furtado, chamou de estudos para compreender a Formação econômica do Brasil. Em seu texto, situou junto da HGCB alguns títulos de Caio Prado Jr., de Roberto Simonsen, de João Antonil, de Pandiá Calógeras, de Afonso Taunay, de Sérgio Milliet e de Alan Manchester (Canabrava, 1975, p.45).

A relevância das análises dos anais da $\mathrm{A}(\mathrm{N}) \mathrm{PUH}$ presta-se à observação da posição de referência assumida pela HGCB e por seu coordenador, Sérgio Buarque de Holanda, no campo da História. Ele teve, nesses anos 1960, a conquista de sua acepção como historiador por meio de um processo que conjugou, de um lado, os itinerários de sua trajetória, responsáveis, direta ou indiretamente, pelo posto de coordenador da HGCB; e, de outro, sua inserção definitiva no espaço acadêmico de ensino superior do Brasil, quando seu nome e textos circularam de forma ampla no seio da comunidade historiográfica.

O caso de Alice Canabrava é sintomático a esse respeito. A historiadora era próxima de Sérgio de longa data, pois ele a havia arguido, quando da defesa de livre-docência, ${ }^{15}$ em 1946, além de terem participado juntos de um Colóquio nos Estados Unidos, comemorativo dos 150 anos da Biblioteca do Congresso americano, em 1950. Mas foi somente em meio ao clima promovido pela conjugação dos fatores HGCB-USP, como espécie de cartão de visitas das principais atividades intelectual-acadêmicas buarqueanas, que as classificações lançadas por ela sobre o autor de Raízes do Brasil passaram a, inequivocamente, qualificá-lo como historiador e a resgatar, também, a (re)leitura de seus escritos anteriores.

Nesse período, emerge, sem dúvida, uma qualificação retrospectiva e positivada sobre os trabalhos de Sérgio Buarque de Holanda. Seja como for, é importante salientar que, fosse para escrever ou falar sobre mineração 
setecentista, distribuição e uso de terras no século XVIII, escravidão no XIX, insurreições, recrutamentos para a vigília de fronteiras, imigração, propriedade, núcleos de colonização ou técnicas na agricultura, entre outras temáticas, muitos textos impressos junto à coleção HGCB surgiam como referências privilegiadas dos estudos de professores e estudantes universitários que se apresentavam nos encontros da A(N)PUH. A HGCB era compreendida como o que de mais novo existia em termos de produção historiográfica no país. Por isso, era citada, bem como seu organizador - uma vez que Sérgio era cada vez mais reconhecido como historiador -, não raro como discurso de autoridade, digna de ser mencionada logo nas notas iniciais das comunicações. ${ }^{16}$

\section{DESLOCAMENTOS CRONOLÓGICO-HISTORIOGRÁFICOS:}

A TÓPICA DO IMPÉRIO SOB A ÓTICA BUARQUEANA

\section{"It's a fascinating period!"}

Com esta exclamação, Sérgio Buarque responde a Richard Graham sobre o período do Império brasileiro. Embora em 1981, momento em que a entrevista se realiza, o autor fosse reconhecido como um dos principais intérpretes do período colonial, o historiador afirmava que seu mais importante livro estava ainda sendo escrito e tinha como objeto o período do século XIX no Brasil. $^{17}$

O interesse do entrevistado pelo Império não era, contudo, recente. Remontava a alguns anos antes quando, ainda na direção da HGCB, havia organizado cinco volumes sobre o período, dando a esse tema um destaque inédito, se comparado com outras coleções que tinham por objetivo explicar o Brasil.

No entanto, a primeira aproximação sistemática de Sérgio Buarque com temas do século XIX fora ainda anterior, e se dera quando ele foi convidado a traduzir, prefaciar e fazer as notas do livro Memórias de um colono no Brasil, do suíço Thomas Davatz (Davatz, 1941). Publicado pela primeira vez em alemão ${ }^{18}$ e registrando a experiência desse imigrante numa das fazendas do Senador Vergueiro, o livro foi impresso em português por iniciativa da editora Martins, na coleção Biblioteca Histórica Brasileira, sob a direção de Rubens Borba de Moraes, em 1941. Ao convidar Sérgio Buarque para esse trabalho, o editor propusera: "Se você acha que seria útil fazer um prefácio-estudo sobre a questão eu te peço que faça ... tenho estudado tanto esse problema que gostaria até de escrever um livro sobre o assunto. Mas eu tenho preguiça de escrever livros. Prefiro 
fazer livros ... Mas você por que não escreve esse livro? Vamos, avante! Faça um prefácio para o Davatz com as diretrizes do futuro livro". ${ }^{19}$

O texto escrito por Holanda para o livro de Davatz acabou por se tornar um marco na historiografia brasileira. Como sugerem alguns pesquisadores, o prefácio contribuiu para consagrar o livro como um documento importante, pois, ao texto traduzido, "Sérgio Buarque acrescentou um conjunto de fontes ... além de extensa bibliografia que se tornou base para uma série de outras pesquisas sobre a temática da emigração e do trabalho livre em São Paulo no século XIX" (Silva, 2012). Como chegou a afirmar um comentarista, "o brilho do prefaciador ofuscou o prefaciado" (Cohen, 2001, p.185). Foi a partir desse trabalho, como sugere o próprio Sérgio, ainda na entrevista a Graham, que temas referentes ao século XIX despertaram seu interesse (Graham, 1982).

Assim, na HGCB, a discussão sobre os movimentos que estabeleceram o início e o fim do Império Brasileiro coube, exclusivamente, a seu diretor. Ao escrever o capítulo inicial - "A herança colonial, sua desagregação" - e o final sobre o Império, que acabou por se constituir no volume $\mathrm{V}$ do tomo II (Do Império à República), Sérgio redefiniu os marcos cronológicos e historiográficos da monarquia no Brasil.

Suas propostas, no entanto, não passariam incólumes entre os leitores. As principais críticas que desencadearam diziam respeito, justamente, à delimitação do período imperial, marca renovadora de seus escritos. A ausência de destaque reservado, por exemplo, ao Sete de Setembro lhe rendeu diversas apreciações desfavoráveis na imprensa que, mesmo elogiando a coleção, cuja escrita da História consideravam seguir bem documentada, não deixavam de avistar também essas questões polêmicas e questioná-las (Silveira, 1960, p.4). Por isso, coube a Sérgio Buarque, como responsável e detentor da fala mais autorizada sobre a HGCB, esclarecer que era "mais plausível datar, não de 1822, mas antes, de 1808, o começo ou o germe das transformações que tender[ão]am a mudar parcialmente a fisionomia social, econômica e cultural forjada durante o tempo da colônia" (Holanda apud Arroyo, 1960, p.3). Ele argumentava que lhe parecia legítimo "fazer parecer imediatamente o estudo da História do Brasil Independente da abordagem da 'fase de transição', que iria de 1808, o ano da chegada da Corte portuguesa, até 1831, o da abdicação e partida do primeiro imperador, nascido, por sua vez, em Portugal" (Holanda apud Arroyo, 1960, p.3).

O esforço da HGCB consistia em buscar compreender melhor o sentido da Independência, separando o movimento de emancipação política da ideia de construção da nacionalidade que, para o diretor da coleção, não ficaria 
assegurada antes de $1848 .{ }^{20}$ No entender de Sérgio Buarque, 1822 por certo "figura como um dos pontos culminantes", mas seria preciso que a data fosse acompanhada por outras do passado brasileiro, "com a Regência, a do Segundo Reinado, finalmente a da República ... relativos à era verdadeiramente nacional da história do Brasil" (Holanda apud Arroyo, 1960, p.3, grifos nossos).

Dessa forma, fica claro o caráter dessacralizante do marco cronológico que estabelecia o início do Império no Brasil e o questionamento dos estudos precedentes sobre o tema, pois o coordenador da HGCB insistia na inexistência de uma unidade territorial e, por assim dizer, de um sentimento nacionalista conjugado à emancipação política. Na percepção de Sérgio Buarque, que assina o capítulo "A herança colonial, sua desagregação", "o 7 de setembro vai constituir simples episódio de uma guerra civil de portugueses, iniciada em 1820, com a revolução liberal portuguesa, e onde se veem envolvidos os brasileiros apenas na sua condição de portugueses do aquém-mar" (Holanda, 2003, p.17-18). Assim, o historiador estabelece novo marco fundador do Império, afirmando que o longo processo de emancipação deveria ser estendido até o Sete de Abril, quando, segundo ele, "o ato de independência ganha um selo nacional” (Holanda, 2003, p.19). Porém, alerta ainda, que "se fosse possível marcar mais nitidamente o remate do processo tendente à unidade nacional ... caberia, talvez, situá-lo por volta de 1848" (Holanda, 2003, p.20).

Se o marco inicial do Império foi amplamente discutido por Sérgio Buarque de Holanda no primeiro volume do Tomo II da coleção, foi no livro intitulado Do Império à República (1972) que se fizeram mais explícitos os argumentos relativos à peculiaridade do passado nacional oitocentista. Esse texto correspondeu ao último volume referente ao Brasil Monárquico e foi totalmente escrito por ele, subvertendo, neste caso, a lógica da coletânea. Nele, Sérgio Buarque lançou a hipótese da crise ministerial como eixo interpretativo basilar para se compreender as instabilidades vivenciadas pelo regime monárquico, sobretudo a partir do Segundo Reinado (1840-1889). ${ }^{21}$

Por essa razão, no início do texto menciona a queda do gabinete do conselheiro Zacarias de Góis e Vasconcelos, em julho de 1868, e a ascensão do Visconde de Itaboraí à frente do governo como um dos fatores representativos do ápice das turbulências políticas recaídas sobre o Império (Holanda, 1972). Ao mobilizar fontes à época inéditas de acervos estrangeiros, como as do National Archives (Washington), referentes a James Watson Webb - então general e plenipotenciário dos Estados Unidos, que entendia como a razão da crise instalada entre São Cristóvão e a Casa Branca a recusa dos militares brasileiros em permitir a passagem de uma embarcação a negócios do governo 
americano até a capital paraguaia, Assunção -, Buarque de Holanda explicou que o entrave se dava por outro fator. Ele seria, em realidade, devido ao contratempo que a permissão poderia causar às estratégias em curso para a conquista de Humaitá, durante a guerra com a nação vizinha. Naquele momento, tal região era decisiva para a vitória da Tríplice Aliança (Brasil, Argentina e Uruguai) sobre as forças comandadas por Solano López e, por esse motivo, o autor não ignorou nem realçou indevidamente o episódio atrelado ao representante estadunidense. Ao reconstituir esses entendimentos oitocentistas, pôde aglutinar outros fatores à deterioração do peculiar regime monárquico brasileiro, criando uma narrativa propícia a tecer uma interpretação histórica que apontava ser, muitas vezes, a simples vontade imperial o elemento responsável pelo desequilíbrio do sistema.

Afinal de contas, enquanto o conselheiro Góis e Vasconcelos se empenhava em evitar o mal-estar e a ruptura com os Estados Unidos, Pedro II não regredia um centímetro de sua decisão de sustentar Luís Alves de Lima e Silva, o Duque de Caxias, no comando do teatro de operações no território platino. Nesse sentido, para Sérgio Buarque, não só a "estabilidade administrativa, que para muitos constitui a grande virtude do regime monárquico, e é sempre esgrimida pelos seus adeptos contra os princípios republicanos, foi exceção na história do Império" (Holanda, 1972, p.9) do Brasil, como também a supremacia absoluta do Poder Moderador constituía o tendão de Aquiles do regime. Logo, nos quadros da tópica imperial despontavam os aspectos da instabilidade, por meio da rotação constante de ministérios, e os da autocracia do rei que, entre outros (des)mandos, promovia o constante revezamento dos partidos no centro decisório da política monárquica.

Mas é claro que, mesmo ante o predomínio de uma ênfase marcadamente política e centrada na análise do Poder Moderador, a ótica buarqueana não se informou apenas dessa esfera do mundo social oitocentista. Para relativizar as balizas cronológicas do Império brasileiro, integrando seu passado à porção continental do Atlântico Sul, a tese de Sérgio Buarque mirou também o aspecto econômico. Não é outra a razão pela qual o desenvolvimento da lavoura paulista adentrou o texto como sinônimo de superação do período colonial, posto que movimentada mais pela mão do trabalhador livre, mormente por imigrantes, tal como seu autor já havia sinalizado no prefácio ao livro de Thomas Davatz. Nesse sentido, a cidade de São Paulo era alocada em uma posição de destaque nos momentos derradeiros do livro Do Império à República. À terra da garoa era assegurada uma posição de vanguarda no sistema de produção 
não tributário da escravização de homens e mulheres vindos da África ou de seus descendentes já em solo americano.

Assim, também o 15 de novembro de 1889 não figuraria como data histórica digna de zelo. Afinal de contas, argumentava Buarque de Holanda, quando se deu início ao movimento para derrubar o regime imperial, com Deodoro da Fonseca à testa do conluio, esse militar, mesmo tendo se encontrado na véspera com Quintino Bocaiúva, Francisco Glicério, Aristides Lôbo e Rui Barbosa, havia se mantido indeciso quanto ao golpe de Estado contra a família real. Em sua narração, escreve que, apesar de Deodoro se dirigir ao quartel para liderar as tropas sublevadas na manhã da precipitação dos acontecimentos, "tudo indicava que o movia uma decisão imperativa" (Holanda, 1972, p.360), em especial, pelo apreço dedicado a Pedro II, amigo pessoal a quem devia favores. Segundo Sérgio Buarque, o militar também reconhecia o avanço da idade de Sua Alteza como um problema à continuidade do regime monárquico, pois seria preciso inaugurar um Terceiro Reinado com a princesa Isabel e o conde d'Eu, figura que não agradava a muitos homens do Império. "Nesse momento, nem ao deixar o portão do quartel-general, estava certo, Deodoro, de que as oligarquias monárquicas pertenciam ao passado, e ia começar o tempo da oligarquia republicana", afirma Buarque de Holanda (1972, p.360).

Com esse ponto final, sem fixar o término efetivo do Império, pois o próprio marechal deixava a caserna imerso em dúvidas, ao se referir à continuação de uma política aristocratizante - uma vez que, por muitas décadas, o povo continuaria excluído dos processos decisórios - e em face do início de uma outra oligarquia, o coordenador da HGCB deixava no ar a tese da República não-proclamada, ${ }^{22}$ como tornou mais explícita numa série de três artigos que publicou em 1979 (Holanda, 1979).

Valorizava-se, assim, uma nova área de estudos - o Brasil Império -, muito embora, paradoxalmente, e é esta a ótica buarqueana na coleção HGCB, a constituição de suas balizas pelos marcos cronológicos de 1822 e 1889 deveria ser amplamente questionada. Logo, ao colocar em xeque os limites do regime imperial no Brasil, pois tratar-se-ia mais da continuidade de uma herança colonial lentamente em fase de desagregação, o plano historiográfico do empreendimento editorial coordenado por Sérgio Buarque de Holanda aproximava o passado brasileiro da história dos demais países americanos, sobretudo os da porção latina. Isso porque, salvo raras exceções, a maioria das nações outrora sob o jugo hispânico alcançou o status político republicano no instante em que se desfez das amarras com as metrópoles europeias. Ao questionar a rigidez cronológica da monarquia implementada na antiga América 
portuguesa e ao diluir a ideia da compreensão do movimento de emancipação como resultado de uma ação nacionalista, a HGCB, por assim dizer, ressaltava aquilo que havia de comum no passado dos países latino-americanos: o fato de os povos da América terem uma origem comum na transmigração de sujeitos portadores da cultura ocidental e, por diferentes que fossem, todos, sem exceção, desenvolverem em maior ou menor medida um legado europeu (Holanda, 1954, p.88).

Também nos textos da HGCB, Sérgio não deixou de mobilizar o velho e seguro método comparativo entre as Américas, a exemplo do que já havia feito em Raízes do Brasil (1936), quando apontou os distintos modus operandi de lusos e castelhanos na colonização dos trópicos; ou em Visão do paraíso (1959) - para ficarmos só nos exemplos mais conhecidos -, quando mostrou quão opostos eram os olhares que portugueses e espanhóis lançavam sobre o Novo Mundo, a propósito do mito edênico.

Na HGCB, o método comparativo serviu, algumas vezes, para aproximar o Brasil do restante da América Latina e, em outras, para propor distinções, como nos livros anteriores. Ao referenciar os abalos institucionais nascidos no momento de implantação do regime republicano, Sérgio Buarque registrou em Do Império à República que as turbulências do fim do Império "tinham efeitos comparáveis aos dos motins políticos que pareciam endêmicos nos países de língua espanhola e embaraçavam, além disso, as medidas que não dessem imediato proveito" (Holanda, 1972, p.9). Porém, ao destacar o período das Regências - cuja distinção é estratégica, se considerarmos sua ótica, que percebia nesse período a antessala de um momento verdadeiramente nacional -, o historiador demonstra como os países da antiga América Espanhola serviam de contraponto político para o Brasil, ao afirmar: "Não custava acreditar como provável ou quase fatal para a antiga América Lusitana, uma sorte idêntica à dos antigos senhorios da Coroa de Espanha, que em muitos aspectos lhe são tão próximos. Mas justamente esse exemplo, longe de constituir um fator de dispersão, fora desde cedo invocado, e nunca o deixará de ser, como um modelo temível que a todo preço convinha evitar" (Holanda, 2003, p.20, grifo nosso).

Como se não bastasse, para sustentar sua ideia da queda do regime, como fruto das contradições institucionais e da centralidade política exercida por Pedro II, o poder deste foi caracterizado como um estorvo frente à necessidade de modernização do sistema imperial, sobretudo, em tempos de mudanças geopolíticas, diante do conflito armado na região do Prata. A própria disputa bélica constituiu-se, na visão de Holanda, como evidência da falta de integração entre as regiões da América Espanhola e Portuguesa. Nesse sentido, a 
respeito dos fracassos iniciais das forças do Império do Brasil no decorrer da Guerra do Paraguai (1864-1870), o autor aponta o desconhecimento das tropas quanto ao montante da população inimiga e escreve acerca das dúvidas que pairavam sobre os planos ou posições das forças de López: "Tudo ali era turvo mistério: assim já sucedera ao tempo das missões dos padres da Companhia, assim continuava a ser sob Francia e seus sucessores" (Holanda, 1972, p.47). A ideia de refletir sobre o enigma populacional e geográfico que o Paraguai representava para os brasileiros era importante para o diretor da $\mathrm{HGCB}$, pois enaltecia as pesquisas desenvolvidas pela coleção sobre o interior do Brasil e suas fronteiras. Não é de espantar, portanto, o registro em Do Império à República segundo o qual, até o momento do conflito armado, "o papel americano do Brasil ainda não fora definido pelos seus homens públicos. Sua emancipação do jugo português foi apenas o prelúdio de um movimento mais amplo que [o] levar[á]ia a ingressar no concerto americano, onde ocupa[va] 'uma formosa porção'” (Holanda, 1972, p.51).

As páginas da HGCB ecoavam, certamente, em grande medida, as palavras anteriormente usadas por Buarque de Holanda, ao abordar o papel distinto do Brasil no espaço do Novo Mundo, na conferência Le Brésil dans la vie américaine, proferida a convite da Organização das Nações Unidas para a Educação, a Ciência e a Cultura (Unesco), em 1954. Ao se referir ao lugar ocupado pelo Brasil e as diferenças culturais, linguísticas e político-sociais em relação aos demais países da América, o autor afirmava que não se poderia deduzir dessas dissensões um isolamento do país no continente ou uma ausência de sentimento de inserção dos brasileiros no mundo americano ou latino-americano. Segundo ele, a despeito da diversidade entre os países da América, o sentimento de pertencimento ao espaço americano sempre teve no Brasil um papel fundamental, o que se evidenciou, por exemplo, quando, ao término da monarquia, a argumentação mais eficaz da propaganda republicana apresentava o império como um regime desatualizado e estranho ao continente (Holanda, 1954, p.88). Porém, afirmava o historiador, não se poderia interpretar o "sentimento americano" como uma forma de patriotismo hemisférico exclusivista. Os povos da América têm uma origem comum a partir da transmigração da cultura ocidental, e é essa dependência de uma cultura vinda de fora que constitui, efetivamente, o traço visível do elo entre esses povos tão distintos (Holanda, 1954, p.88).

As páginas da HGCB possivelmente reverberavam também a aproximação que, ao longo dos anos 1960, Buarque de Holanda empreendeu com universidades e grupos de pesquisa dos mais diversos países da América. Nesse 
período, o professor da USP recebeu inúmeros convites para ministrar cursos em universidades estrangeiras, por intermédio de intercâmbios culturais. Diversos pedidos lhe foram dirigidos por instituições estadunidenses Universidades Columbia, Harvard, de Los Angeles, Indiana, New York -, tanto por iniciativa do embaixador americano no Brasil, Lincoln Gordon, quanto diretamente por professores, que lhe relatavam o interesse pelos estudos sobre o país e informavam sobre a estrutura de que dispunham para realizá-los. ${ }^{23}$ Mas os chamados não partiam somente dos Estados Unidos. Também o Centro de Investigações especializadas em História Americana (CIHA), no Chile, que contava com apoio financeiro da Fundação Rockefeller (EUA), convidou Sérgio Buarque em 1962 para proferir um curso que tinha como objetivo estimular a pesquisa e o ensino da História da América. Eugenio Pereira Salas convocou-o para integrar, no ano letivo de 1963, uma disciplina que teria aulas divididas em três unidades sobre o continente, iniciando pelo estudo do Brasil ${ }^{24}$ e sendo seguido por partes referentes à América Espanhola - que ficaria a cargo do historiador Ruggiero Romano, italiano catedrático da École Pratique des Hautes Études (Paris) - e aos Estados Unidos, sob a liderança de Max Savelle, estadunidense, professor na Universidade de Washington (Seattle). ${ }^{25}$

Assim, pode-se crer que Sérgio Buarque de Holanda vivia, nessa época, uma fase de busca pelo estabelecimento de laços historiográficos, que se marcava pelo desejo de escrever uma História comum das Américas. Dessa forma, fosse por meio da abordagem como contraponto, fosse como proximidade, a história da antiga América Espanhola foi tomada, em seus escritos na HGCB, como via especular para a compreensão da história do Brasil. É possível afirmar que a história do Império desenvolvida por Sérgio Buarque, à testa da coleção, sugeria um olhar integrado do Brasil à América. A ótica buarqueana mantinha, num só tempo, sua crítica ao passado colonial luso - com vistas a superá-lo - e o questionamento dos marcos cronológicos e historiográficos do Império, o que o constituía como uma peculiaridade brasileira, sem deixar de situá-lo no interior do debate sobre o conjunto das nações do Novo Mundo Ibérico.

\section{REFERÊNCIAS}

ABREU, Capistrano de. Capitulos de história colonial. Rio de Janeiro: Orosco, 1907. ARROYO, Leonardo. Vida literária. A abordagem da história do Brasil. Folha de S. Paulo, São Paulo, 6 jul. 1960, p.3. Disponível em: http://acervo.folha.com.br/; Acesso em: 8 abr. 2016. 
ASSIS, Arthur. A teoria da história com hermenêutica da historiografia: uma interpretação de Do Império à República, de Sérgio Buarque de Holanda. Revista Brasileira de História, São Paulo: Anpuh, v.30, n.59, p.91-120, jan./jun. 2010.

CANABRAVA, Alice P. A indústria do açúcar nas ilhas inglesas e francesas do Mar das Antilhas. Data: 7-VII-1946. Centro de Apoio à Pesquisa em História. Faculdade de Filosofia, Letras e Ciências Humanas da Universidade de São Paulo (CAPH-FFLCH).

Uma perspectiva para a formação econômica do Brasil. In: SIMPÓSIO NACIONAL DOS PROFESSORES UNIVERSITÁRIOS DE HISTÓRIA, 8., 1975, Aracaju. Anais..., p.45. Disponível em: http://anpuh.org/anais/wp-content/uploads/ ANPUH.S08.pdf; Acesso em: 7 abr. 2016.

CARDOSO, Fernando H. Rio Grande do Sul e Santa Catarina. In: HOLANDA, Sérgio B. de (Org.) História Geral da Civilização Brasileira (t. II). Dispersão e unidade (v.2). São Paulo: Difel, 1964. p.473-508.

CARVAlHO, José M. de. Os bestializados. São Paulo: Companhia das Letras, 1987.

CASTRO, Acyr. Difusão Europeia do Livro, um programa humanista. Jornal do Brasil, Rio de Janeiro, 6 abr. 1974, p.46.

CASTRO, Jeanne B. de. A guarda nacional. In: HOLANDA, Sérgio B. de (Org.) História Geral da Civilização Brasileira (t. II). Declínio e queda do Império (v.4). São Paulo: Difel, 1971. p.274-298.

.; SCARANO, Júlia Maria L. A mão de obra escrava e estrangeira numa região de economia cafeeira (1875-1930). In: SIMPÓSIO NACIONAL DOS PROFESSORES UNIVERSITÁRIOS DE HISTÓRIA, 6., 1971, Goiânia. Anais... p.718. Disponível em: http://anpuh.org/anais/wp-content/uploads/ANPUH.S06.pdf; Acesso em: 8 abr. 2016.

COHEN, Ilka S. Thomas Davatz revisitado: reflexões sobre a imigração germânica no século XIX. Revista de História, São Paulo: DH/FFLCH/USP, v.144, p.181-211, 2001. Disponível em: http://www.revistas.usp.br/revhistoria/article/ view/18914/20977.

CROUZET, Maurice (Dir.) História Geral das Civilizações. São Paulo: Difel, 1955-1958.

DAVATZ, Thomas. Memórias de um colono no Brasil (1850). São Paulo: Martins, 1941. (Biblioteca Histórica Brasileira).

DEAN, Warren. A ferro e fogo: a história e a devastação da Mata Atlântica brasileira. Trad. Cid Knipel Moreira. São Paulo: Companhia das Letras, 1996.

. História Geral da civilização Brasileira: o Brasil monárquico. Part 2: Dispersão e unidade, by Sérgio Buarque de Holanda. 1967. Hispanic American Historical Review, Durham, NC: Duke University Press, v.47, n.2, p.299-300, May 1967. 
DIAS, Maria Odila L. da S. A interiorização da metrópole (1808-1853). In: MOTA, Carlos G. (Org.) 1822: dimensões. São Paulo: Perspectiva, 1972. p.160-184. (Debates, v.67).

DUTRA, Eliana de F. A nação nos livros. A biblioteca ideal na Coleção Brasiliana. In: .; MOLLIER, Jean-Yves (Org.) Política, nação e edição: o lugar do impresso na construção da vida política. Brasil, Europa e Américas nos séculos XVIII-XX. São Paulo: Annablume, 2006. p.299-314.

ELLIS, Myriam. Noticiário. Concurso para provimento da cadeira de História da Civilização Brasileira da Faculdade de Filosofia, Ciências e Letras da Universidade de São Paulo. Revista de História, São Paulo: FFCL-USP, ano X, n.38, p.493-508, abr./ jun. 1959.

FATOS e autores. História Geral da Civilização Brasileira. Folha de S. Paulo, São Paulo, 7 fev. 1960, p.4. Disponível em: http://acervo.folha.com.br/; Acesso em: 29 mar. 2016.

FURTADO, André. As edições do cânone: da fase buarqueana na coleção História Geral da Civilização Brasileira (1960-1972). Niterói: Ed. UFF, 2016.

GONTIJO, Rebeca. O velho vaqueano: Capistrano de Abreu, da historiografia ao historiador. Tese (Doutorado em História) - Universidade Federal Fluminense (UFF). Niterói, 2006.

GRAHAM, Richard. An interview with Sérgio Buarque de Holanda. Hispanic American Historical Review, Durham, NC: Duke University Press, v.62, n.1, p.3-17, Feb. 1982. HALLEWELL, Laurence. O livro no Brasil: sua história. São Paulo: Edusp, 1985. HOLANDA, Sérgio B. de. Le Brésil dans la vie américaine. In: LE NOUVEAU MONDE ET L'EUROPE. Rencontres internationales de Genève et Rencontres intellectuelles de São Paulo, 1954. Tome IX. Neuchâtel: Les Éditions de la Baconnière; Unesco, 1954.

. Capitulos de história do império (org. e introd. Fernando Novais). São Paulo: Companhia das Letras, 2010.

. A herança colonial, sua desagregação. In: (Org.) História Geral da Civilização Brasileira (t. II). O processo de emancipação (v.1). 9.ed. Rio de Janeiro: Bertrand Brasil, 2003. p.13-47.

. História Geral da Civilização Brasileira (t. II). Do Império à República (v.5). São Paulo: Difel, 1972.

. Os projetos de colonização e comércio toscanos no Brasil ao tempo do grão-duque Fernando I (1587-1609). In: SIMPÓSIO NACIONAL DOS PROFESSORES UNIVERSITÁRIOS DE HISTÓRIA, 4., 1967, Porto Alegre. Anais... p.157. Disponível em: http://anpuh.org/anais/wp-content/uploads/ANPUH.S04.A.pdf; Acesso em: 7 abr. 2016.

. Uma república não-proclamada III. Jornal da República, São Paulo, 20 nov. 1979. 
HOLANDA, Sérgio B. de. In: São Paulo. In: (Org.) História Geral da Civilização Brasileira (t. II). Dispersão e unidade (v.2). São Paulo: Difel, 1964. p.413-472. .; ROMANO, Rugierro; SAVELLE, Max. Tres lecciones inaugurales. Santiago de Chile: Centro de Investigaciones de Historia Americana/Universidad de Chile, 1963.

IGLÉSIAS, Francisco. Minas Gerais. In: HOLANDA, Sérgio B. de (Org.) História Geral da Civilização Brasileira (t. II). Dispersão e unidade (v.2). São Paulo: Difel, 1964. p.364-412.

KERN, Fritz et al. (Ed.) Historia mundi (10v.) Bern: Francke-Verlag, 1952-1961.

LIVROS: mercado interno. Jornal do Brasil, Rio de Janeiro, 6 jun. 1960, p.42.

LOBATO, Sidney da S. Estado, nação e região na obra de Arthur Cezar Ferreira Reis. Diálogos, Maringá: UEM, v.13, n.3, p.625-642, 2009.

MOUTINHO, Nogueira. Paul Jean Monteil. Folha de S. Paulo, São Paulo, 7 dez. 1973, p.3. Disponível em: http://acervo.folha.com.br/; Acesso em: 1 abr. 2016.

PANTALEÃO, Olga. A presença inglesa. In: HOLANDA, Sérgio B. de (Org.) História Geral da Civilização Brasileira (t. II). O processo de emancipação (v.1). São Paulo: Difel, 1962. p.64-99.

POTTER, Richard G. et al. (Ed.) The new Cambridge Modern History (14v.). Cambridge: Cambridge University Press, 1957-1979.

REIS, Arthur Cezar F. O comércio colonial e as companhias privilegiadas; Inquietações no Nordeste \& A inconfidência baiana. In: HOLANDA, Sérgio B. de (Org.) História Geral da Civilização Brasileira (t. I). Administração, economia, sociedade (v.2). São Paulo: Difel, 1960b. p.311-339, 380-393, 411-417.

A ocupação portuguesa do vale amazônico \& Os tratados de limites. In: HOLANDA, Sérgio B. de (Org.) História Geral da Civilização Brasileira (t. I). Do descobrimento à expansão territorial (v.1). São Paulo: Difel, 1960a. p.257-272, 364-380.

. As regiões brasileiras: formação, peculiaridades e integração... In: SIMPÓSIO DE PROFESSORES DE HISTÓRIA DO ENSINO SUPERIOR, 1., 1961, Marília. Anais..., p.66-67. Disponível em: http://anpuh.org/anais/?tag=s01; Acesso em: 7 abr. 2016.

SALVADOR, Vicente do (Frei). História do Brasil: 1500-1627. 2.ed. Revisão e prefácio por João Capistrano de Abreu. São Paulo: Weizflog Irmãos, 1918.

SILVA, Raul P. Modernismo, historiografia e sociabilidade intelectual: apontamentos sobre o quinto volume da coleção Biblioteca Histórica Brasileira (1931-1940). História, São Paulo: DH/FFLCH/USP, v.31, n.2, jul./dez. 2012.

SILVEIRA, Homero. Opiniões. História Geral da Civilização Brasileira. Folha de S. Paulo, São Paulo, 29 maio 1960, p.4. Disponível em: http://acervo.folha.com.br/; Acesso em: 25 abr. 2016.

TATON, René (Dir.) História Geral das Ciências. São Paulo: Difel, 1959-1967. 
VENANCIO, Giselle M. Brasiliana segunda fase: percurso editorial de uma coleção que sintetiza o Brasil (1956-1993). In: DUTRA, Eliana (Org.) O Brasil em dois tempos. Belo Horizonte: Autêntica, 2013. p.109-126.

. Da Revista do Brasil ao Brasil em revista: breve análise da trajetória editorial de Oliveira Vianna. Varia História, Belo Horizonte: PPGH-UFMG, v.18, n.26, p.132-150, jan. 2002.

.; FURTADO, André. Brasiliana \& História Geral da Civilização Brasileira: escrita da história, disputas editoriais e processos de especialização acadêmica (1956-1972). Revista Tempo e Argumento, Florianópolis: PPGH-UDESC, v.5, n.9, p.5-23, jan./jun. 2013.

.; SILVA, Ítala Bianca M. da. Um tal João, um tal Francisco: disputas intelectuais e monumentalização da produção intelectual de Capistrano de Abreu e Oliveira Vianna nos anos 50. In: PEREIRA, Mateus et al. (Org.) Contribuições à história da historiografia luso-brasileira. São Paulo: Hucitec; Belo Horizonte: Fapemig, 2013. p.389-424.

WRIGHT, Antônia Fernanda de A. Alguns documentos interessantes referentes à América do Sul e Caribe pertencentes ao acervo do Scottish Record Office. In: SIMPÓSIO DOS PROFESSORES UNIVERSITÁRIOS DE HISTÓRIA, 3., 1965, Franca. Anais..., p.555-556. Disponível em: http://anpuh.org/anais/wp-content/ uploads/ANPUH.S03.pdf; Acesso em: 7 abr. 2016.

\section{NOTAS}

${ }^{1}$ É preciso realçar que, embora a coleção tenha sido editada somente a partir de 1960, as negociações para sua publicação datam ao menos de 1957, portanto, antes que Sérgio Buarque de Holanda assumisse de forma definitiva a cátedra de História da Civilização Brasileira na Universidade de São Paulo (USP). A comprovação de que o convite de Monteil e o projeto já estavam em curso antes que a tese Visão do paraíso fosse aprovada no concurso, pode ser evidenciada por uma carta de Rubem Lima a Américo Jacobina Lacombe - à época seu coordenador da coleção Brasiliana - comentando sobre plano geral de uma nova coleção da Difel que teria Sérgio Buarque como diretor. Cf. Arquivo Américo Jacobina Lacombe. Fundação Casa de Rui Barbosa (FCRB). Pasta Correspondência. Direção da Brasiliana. Carta de Rubem Lima, de 28 out. 1957, pasta 291.

${ }^{2}$ Os volumes publicados até 1967 foram: Do descobrimento à expansão territorial \& Administração, economia, sociedade, do Tomo I (A Época Colonial), ambos editados em 1960, bem como O processo de emancipação (1962), Dispersão e unidade (1964), e Reações e transações (1967), do Tomo II (O Brasil Monárquico).

${ }^{3} \mathrm{O}$ interesse de Warren Dean pela América Latina teve início quando se pós-graduou nos anos 1950 com um estudo sobre Cuba, cuja revolução, em 1959, provocou o fechamento da ilha aos cidadãos estadunidenses. Por isso voltou-se para o Brasil, sobre o qual publicou, 
entre outros, um estudo que se tornou referência para a História Ambiental: Ferro e fogo (DEAN, 1996).

${ }^{4}$ No entanto, é interessante notar a existência de registros que apontam o interesse de Sérgio Buarque, décadas antes de coordenar a HGCB, por um tipo de reflexão integradora do continente. Ao terminar, nos anos 1930, sua experiência como enviado especial d'O Jornal, em Berlim, teria retornado ao Brasil com escritos que deveriam se tornar um livro - jamais impresso ou encontrado em seus arquivos - previamente intitulado Teoria da América. Em entrevista a Richard Graham afirmou que, das quase 400 páginas do rascunho desse livro, retirou ao menos dois capítulos para escrever Raízes do Brasil. Cf. GRAHAM, 1982, p.6.

${ }^{5}$ Para se aprofundar na coleção Brasiliana e seus diretores, ver: DUTRA, 2006; VENANCIO, 2013. Sobre as relações entre os intelectuais e seus trânsitos nesses projetos, ver: VENANCIO; FURTADO, 2013; FURTADO, 2016.

${ }^{6}$ Durante sua existência, a Documentos Brasileiros foi coordenada por Gilberto Freyre, até 1939, sucedido por Octávio Tarquínio de Sousa, que só a deixou cerca de 20 anos depois. A diretoria da coleção ficou vaga ao menos até 1962, quando passou a Afonso Arinos de Mello Franco.

${ }^{7}$ Aos 56 anos de idade, Sérgio se tornou professor efetivo de ensino superior, ao assumir a cátedra na USP, em 1958. Antes havia atuado em outras instituições: como professor assistente e adjunto durante os anos 1930, na Universidade do Distrito Federal (UDF/Rio de Janeiro); docente no Curso de Biblioteconomia instituído pela Biblioteca Nacional (BN), em 1945; professor entre 1947 e 1955 (com algumas interrupções) na Escola Livre de Sociologia e Política (ELSP/São Paulo); como visitante na Universidade de Roma (1952-1954); professor na Universidade de Sorocaba (SP). Cf. Série: Vida Pessoal. 88 - Curriculum Vitae de SBH. 1958. (c/ anot. ms.) Vp 88 P242. Fundo SBH. Siarq-UNICAMP.

${ }^{8}$ O francês Paul Jean Monteil (1907-1973) era engenheiro. Chegou ao Brasil em 1937 para trabalhar na área têxtil, mas ao promover uma greve na empresa que o empregou saiu desse ramo e se encaminhou para o setor editorial.

${ }^{9}$ Wanderley de Araujo Pinho compusera, com os professores Afonso Arinos de Mello Franco (catedrático de Direito Constitucional na UDF); Hélio Viana (catedrático de História do Brasil da Faculdade Nacional de Filosofia, FNFi/Rio de Janeiro); Eduardo d'Oliveira França (catedrático de História Moderna e História Contemporânea na USP); e Eurípedes Simões de Paula (catedrático de História Antiga e História Medieval também na USP), a banca do concurso catedrático que avaliou Sérgio Buarque na USP. Cf. ELLIS, 1959.

${ }^{10}$ Quando da arguição a Sérgio Buarque na USP, em 1958, Araújo Pinho já integrava o grupo de colaboradores escolhidos para participar da coleção HGCB. Cf. Pinho, 1964; Série: Correspondência. Subsérie: Passiva. 455 - Carta de Wanderley Pinho a SBH, pedindo prorrogação do prazo para que entregasse um trabalho. Rio de Janeiro, 6 jul. 1961. as. Wanderley Pinho. 1p. Cp 233 P9. Fundo SBH. Siarq-UNICAMP. 
${ }^{11}$ Arquivo do Instituto de Estudos Brasileiros (IEB) USP - Fundo Alice Piffer Canabrava, APC-P1, 01. Carta. 28.06.1960. Belo Horizonte (MG). Remetente: Francisco Iglésias. Considerada essa fonte, é válido frisar que, mesmo diante de dúvidas e do elogio à versão francesa das Histórias gerais, tanto Canabrava quanto Iglésias viriam a colaborar na coleção HGCB, após a troca dessa missiva. Cf. IGLÉSIAS, 1964.

${ }^{12}$ Amazonense formado em Direito pela Faculdade de Ciências Jurídicas e Sociais do Rio de Janeiro (1927), Reis atuou na imprensa e chegou a lecionar na UFF. Antes disso, vinculado à política partidária de seu estado, foi indicado pelo marechal Castelo Branco para assumir o governo do Amazonas (1964-1967), após o golpe de 1964. Quando passou à docência na UFF, já integrava os Institutos Históricos (nacional e regional) e contava com uma bagagem de pesquisa marcada por um largo trânsito em estudos sobre a região amazônica. Cf. LOBATO, 2009.

${ }^{13}$ Naquele momento existia um processo que visava refundar a História do Brasil a partir da obra de Capistrano de Abreu (GONTIJO, 2006). Ao ser alçado à posição de referência, sobretudo nos temas do chamado período colonial, pode-se dizer que seus estudos foram apropriados como um elo entre a historiografia do século XIX e aquela que o sucederia na escrita da história nacional. Cf. VENANCIO; SILVA, 2013.

${ }^{14}$ Até então, os cinco textos que o historiador amazonense havia publicado eram os seguintes: A ocupação portuguesa do vale amazônico; Os tratados de limites; O comércio colonial e as companhias privilegiadas; Inquietações no Nordeste e A inconfidência baiana (REIS, 1960).

${ }^{15}$ Cf. CANABRAVA, 1946; Vida Pessoal. 88, op. cit., Vp 88 P242. Fundo SBH. Siarq-UNICAMP.

${ }^{16} \mathrm{O}$ mesmo não ocorre em espaços de difusão do saber de caráter interdisciplinar, como a Revista do Instituto de Estudos Brasileiros (IEB), mesmo tendo Buarque de Holanda ajudado a fundar e presidido a primeira diretoria do IEB (1962-1964). Logo, cabe salientar que seu reconhecimento como historiador deu-se por suportes próprios do campo da História, a exemplo dos anais da $\mathrm{A}(\mathrm{N}) \mathrm{PUH}$, provavelmente pari passu à especialização dos estudos universitários que se estabeleciam.

${ }^{17}$ Referia-se à escrita da obra inconclusa e só postumamente conhecida sob o título de Capitulos de História do Império, publicada pela Companhia das Letras, com Nota Introdutória e organização do historiador Fernando Novais. Tratava-se de cerca de 150 páginas datilografadas que Buarque de Holanda vinha escrevendo até pouco antes de morrer, em 1982, como parte do aprimoramento que empreendia sobre o último volume que publicou na coleção HGCB, ou seja, o livro Do Império à República (1972). Cf. HOLANDA, 2010.

${ }^{18}$ Die behandlung der Kolonisten in der Provinz São Paulo in Brasilien und deren Erhebung gegen ihre Bedrücker. Ein Noth-und Hilfruf an die Behörden und Menschenfreunde der Länder und Staaten, welchen die Kolonisten angerhörten, Chur, 1858, apud COHEN, 2001, p.185.

${ }^{19}$ Carta de Rubem Borba de Moraes a Sérgio Buarque de Holanda (18-05-1940), apud COHEN, 2001, p.184-185. 
${ }^{20} \mathrm{Um}$ dos estudos posteriormente orientados por Sérgio Buarque, o de Maria Odila Dias, seguiu a mesma linha historiográfica ao sinalizar a existência de um "localismo" nas relações de poder nos períodos colonial e imperial. Assim, se houve um movimento nacionalista, este só se deu, nas palavras de Dias, "Algumas décadas após a independência (18381870) [quando] chegariam os ilustrados brasileiros a definir seu nacionalismo didático, integrador e progressista e uma consciência social eminentemente elitista e utilitária" (DIAS, 1972, p.184).

${ }^{21}$ Embora tenha optado pela análise isolada do volume Do Império à República, sem atentar para a coleção HGCB, foi o pesquisador Arthur Assis quem nos forneceu a pista sobre as noções de crise no Segundo Reinado e poder pessoal de Pedro II como elementos explicativos do texto de Sérgio Buarque. Cf. ASSIS, 2010.

${ }^{22}$ É interessante observar que essa tese buarqueana parece ecoar no estudo de José Murilo de Carvalho, que usa a expressão “A República que não foi”, sem que Do Império à República, de 1972, ou os artigos posteriormente publicados por Sérgio Buarque, em 1979, apareçam citados. Do intelectual paulista só menciona a primeira edição de Raízes do Brasil, de 1936, que não comportava essa ótica sobre a monarquia. Cf. CARVALHO, 1987.

${ }^{23}$ Exemplo disso é a carta do historiador Brandford Burns, que destacou: “The University offers courses on Brazilian history and geography and sponsors one of the even Portuguese language centers in this country". Série: Correspondência. Subsérie: Passiva. 490 - Carta de E. Bradford Burns da Universidade da Califórnia a SBH convidando-o para que fizesse uma visita à UCLA. Los Angeles, 15 mar. 1965. as. E. Bradford Burns. 1p. Cp 268 P10. Fundo SBH. Siarq-UNICAMP.

${ }^{24}$ Série: Correspondência. Subsérie: Passiva. 470 - Carta em espanhol de Eugenio Pereira Salas a SBH, convidando-o para que ministrasse um curso sobre História do Brasil no Centro de Investigaciones de História Americana. Santiago de Chile, 14 dez. 1962. as. ileg. 1p. Cp 248 P9. Fundo SBH. Siarq-UNICAMP.

${ }^{25}$ Nesse mesmo ano o curso foi impresso no formato de livro: Cf. HOLANDA; ROMANO; SAVELLE, 1963.

Artigo recebido em 27 de junho de 2016. Aprovado em 26 de agosto de 2016. 